\title{
A linguistically-motivated annotation model of modality in English and Spanish: Insights from MULTINOT
}

\author{
Julia LAVID, Marta CARRETERO AND JuAn RAFAel \\ ZAMORANO-MANSILLA, Universidad Complutense de Madrid
}

\begin{abstract}
In this paper we present current work on the design and validation of a linguistically-motivated annotation model of modality in English and Spanish in the context of the MULTINOT project. ${ }^{1}$ Our annotation model captures four basic modal meanings and their subtypes, on the one hand, and provides a fine-grained characterisation of the syntactic realisations of those meanings in English and Spanish, on the other. We validate the modal tagset proposed through an agreement study performed on a bilingual sample of four hundred sentences extracted from original texts of the MULTINOT corpus, and discuss the difficult cases encountered in the annotation experiment. We also describe current steps in the implementation of the proposed scheme for the large-scale annotation of the bilingual corpus using both automatic and manual procedures.
\end{abstract}

\footnotetext{
${ }^{1}$ The MULTINOT project is financed by the Spanish Ministry of Economy and Competitiveness, under grant number FF2012-32201. We gratefully acknowledge the support provided by the Spanish authorities. We also thank the comments and suggestions provided by the anonymous reviewers which have helped to improve the current manuscript.
} 


\section{Introduction}

In this paper we describe the construction and empirical validation of a modality annotation scheme for English and Spanish in the context of the MULTINOT project, whose main aim is the development of a parallel English-Spanish corpus which is balanced - in terms of register diversity and translation directions - and whose design and enrichment with multiple layers of linguistic annotations focuses on quality rather than on quantity (see Lavid et al. 2015) ${ }^{2}$.

One of the most relevant annotation tasks within MULTINOT focuses on the category of modality in English and Spanish, not only for its theoretical interest as a topic of contrastive research between these two languages, but also for its computational relevance in the NLP community, where modally-annotated corpora are an indispensable resource for training systems to automatically interpret modality. Practical NLP applications such as textual entailment, information extraction, question answering, sentiment analysis and machine translation need to be able to distinguish automatically modal from actual information as part of the complete understanding of a text. In response to this need, the last years have witnessed the development of annotations schemes and annotated corpora for different aspects of modality in different languages (McShane et al. (2004), Wiebe et al. (2005), Szarvas et al. (2008), Saurí and Pustejovsky (2009), Hendrickx et al. (1973), Baker et al. (2012)).

However, the annotation of modal meaning is a complex task, as will be shown in the remainder of this paper. The difficulties derive not only from the practicalities of the annotation process, but also from the subtle distinctions which emerge in the modal domain. In addition, when the task involves more than one language, the complexity increases, given the language-specific features that have to be considered in the annotation process.

To our knowledge, there are no annotation schemes for modality which specifically address the commonalities and the language-specific features of English and Spanish, although there are various proposals for English and for other languages. The present work tries to fill a gap in this area by approaching the annotation of modality from two interrelated perspectives: (a) the functional/semantic perspective,

\footnotetext{
${ }^{2}$ The MULTINOT corpus consists of original and translated texts in both directions summing up a total of half a million words (see Lavid et al. 2015). It includes a wide variety of registers to make it a multifunctional resource which can be used in a number of disciplines such as corpus-based contrastive linguistic and translation studies, machine translation, computer-assisted translation, computer-assisted language learning and terminology extraction.
} 
which captures the commonalities shared between both languages in the creation of modal meanings, and (b) the syntactic perspective, which considers the language-specific preferences in the encoding of similar modal meanings in English and Spanish. This approach allows us to discover the form-function correspondences of different modal values in English and Spanish, which will be useful not only from a theoretical linguistic perspective, but also for computational applications where language comparison is central, such as Machine Translation and Computer-aided Translation.

The paper is structured as follows. We first present our theoretical background and discuss some related work (section 2). We then outline some basic decisions which have guided our annotation proposal (section 3). In section 4 we present the common functional/semantic tagset proposed, which captures four basic modal meanings and their subtypes in both English and Spanish, namely, epistemic/evidential, deontic, dynamic and volitional, and describe each of these meanings in subsections $4.1,4.2,4.3$ and 4.4., respectively. In section 5 we describe the latest in a series of annotation experiments to validate the proposed tagset (5.1), report on the results obtained through several interannotator agreement studies (5.2) and discuss the difficult cases (5.3). Section 6 presents the language-specific tagsets for each of the modal meanings proposed and section 7 focuses on the implementation of the annotation scheme using the UAM Corpus Tool. Finally, section 8 summarises the work and concludes with some pointers for the future.

\section{Theoretical background and related work}

In the linguistics community there is an extensive body of research on English modality which has focused on the conceptualisation of this broad category in terms of a number of meanings, the most common labels being 'epistemic', 'deontic' and 'dynamic' (Perkins 1983, Palmer 1990, Collins 2009, among others). In addition, some scholars have also included 'boulomaic' or 'volitional' modality to capture meanings concerned with willingness, intention or wish. While the first three macro-categories ('epistemic', 'deontic' and 'dynamic') constitute what is known as 'core modality', the last one is considered by some scholars as 'peripheral'. We share Nuyts' (Nuyts, 2005, 24) viewpoint that the main reason for this different consideration lies in the historical predominance of form-oriented studies in the literature on modality, with many references concentrating on the modal auxiliaries. As will be seen in the remainder of the article, 'epistemic', 'deontic' and 'dynamic' modality can be expressed by all the modal auxiliaries in English and 
by several periphrases in Spanish, while 'volitional' modality is mainly realised by other expressions. In English, the only modal auxiliaries that can express volitional modality are will and would, and in Spanish its most grammaticalised realisation is the future tense, followed by the construction querer + infinitive. However, notional approaches to modality based on meaning rather than form have increased in the last two decades, with the consequence that volitional modality is increasingly considered as a modality on a par with the others: for example, Nuyts (2005) advocates for a category of 'boulomaic attitude', and Portner (2009) includes a 'bouletic' modality. Moreover, volitional modality shares a number of features with the other modalities: for example, it conveys an attitude of the addresser (speaker or writer) towards what is communicated (Carretero et al., 2007, 92-94). For these reasons, we consider volitional modality as a modal category, together with the epistemic, deontic and dynamic. The four basic modalities can be briefly characterised as follows:

- Epistemic modality, described in terms of 'rational laws' by Perkins (1983), refers to degrees of probability, i.e. the speaker/writer's estimation of the chances that a proposition has for being or becoming true. Examples of this type are illustrated by (1) and (2) below: ${ }^{3}$

(1) He thinks of Rupert Parrott, the publisher, who might pay him to read manuscripts. He does not think he will pay much, but it might be enough.(EO-FICTION-011)

(2) Somewhere in the world at that ancient date, at least one of my personal ancestors must have been living, or I wouldn't be here. Let us call this particular little mammal Henry (it happens to be a family name). (EO-EXPE-006)

- Deontic modality is based on social laws (Perkins, 1983) and concerns obligation (3), recommendation (4), permission (5) and prohibition (6):

(3) Telecoms touches everything - and users are developing massive expectations of it. Markets must function, devices must function, networks must function and investment needs to happen. (EOSPEECH-012)

(4) Population growth is therefore not a reason against giving overseas aid, although it should make us think about the kind of aid to give. (EO-ESSAY-010)

${ }^{3}$ All examples have been extracted from different registers of the MULTINOT corpus. The modal trigger is in bold, and the reference in parenthesis indicates the language (EO stands for English original, ESSAY is the register type, and the three digits constitute the text identification number). 
(5) I'm here simply to listen. You can tell me anything. That's what I'm for." (EO-FICTION-011)

(6) You must not modify the paper or digital copies of any materials you have printed off or downloaded in any way (EO-WEBP-007)

- Dynamic modality has been described by Perkins (1983) as possibility and necessity derived from natural laws (i.e. those of physics, chemistry, biology, etc.). Dynamic modality includes the meanings of necessity, tendency, ability, natural possibility and natural impossibility. Examples (7) and (8) below illustrate the meanings of natural possibility and ability, respectively:

(7) Tracing ancestors is a beguiling pastime. As with history itself, there are two methods. You can go backwards, listing your two parents, four grandparents, eight great-grandparents, and so on. Or you can pick a distant ancestor and go forwards, listing his children, grandchildren, great-grandchildren, until you end up with yourself. (EO-EXPE-006)

(8) Today, for example, a patient in New York may have his MRI sent digitally to, say, Bangalore, where a highly skilled radiologist reads it for one-quarter of what a New York-based radiologist would cost. But how long will it be before a computer software can read those images faster, better, and cheaper than the radiologist in Bangalore can? (EO-ESSAY-009)

- Volitional modality covers as a scale of degrees of wish, its middle point being acceptance (Carretero 1992; Carretero et al. 2007). Examples (9) and (10) express willingness and acceptance, respectively:

(9) When people search Google for an address, they do not want a link to Web sites that mention the street. They usually want to know how to get there. (EO-ESSAY-008)

(10) Perhaps the most remarkable achievement of the Hong Kong Ministerial was the acceptance by other developed countries to follow us some of the way by granting duty free/quota free access to $97 \%$ of the products originating in least developed countries, (EO-SPEECH-003)

As to the literature on practical corpus annotation of modality, previous research has targeted mostly English texts, and most of the work has focused on modal auxiliaries and verbs, and on the distinction between factual (actual) and non-factual (modal) information, since this is necessary for a number of NLP tasks such as textual entailment (Burchardt and Frank 2006, Saurí and Pustejovsky 2009), information extraction (Karttunen and Zaenen, 2005), question answering (Saurí 
et al., 2006), sentiment analysis (Wiebe et al., 2005), and machine translation (Baker et al., 2012). Given the need for high-quality annotated datasets with modal features, projects on other languages have also been developed during the last years (see Hendrickx et al. 1973, McShane et al. 2004, Wiebe et al. 2005, Szarvas et al. 2008, Saurí and Pustejovsky 2009, Baker et al. 2012). Also, previous work by the authors of this paper has focused on the annotation of specific linguistic expressions in English and Spanish (i.e. modal verbs and certain adverbs), with the aim of distinguishing modal and non-modal realisations of each of the expressions, as well as the more theoretical aim of setting forth the subsequent implications for determining the concept and scope of modality (see Lavid et al. 2015, Carretero and ZamoranoMansilla 2013a, Carretero and Zamorano-Mansilla 2013b, ZamoranoMansilla and Carretero 2012). However, a concrete proposal for the annotation of modality in Spanish as a functional category with characteristic realisational features does not yet exist, and, to our knowledge, there are no practical annotation schemes which consider the annotation of English and Spanish bilingual texts. ${ }^{4}$

An interesting proposal was put forward by Nissim et al. (2013). These authors propose a cross-linguistic annotation model of modality which works with two layers: a functional layer, which allows them to use the same modal categories across languages, and a linguistic layer, which captures the syntactic nature of the modal triggers. Our own proposal is similar to theirs in proposing two distinct layers of annotation to capture both the functional/semantic commonalities between English and Spanish and the language-specific syntagmatic realisations. However, it differs in several respects: first, it is more fine-grained in terms of the modal meanings included in our annotation scheme; second, we do not include the notion of factuality in our annotation model since this is a separate dimension which cuts across the four basic modal meanings but does not serve to establish distinctions between them. Third, we propose a more concrete and linguistically-sophisticated specification of the syntagmatic options available to English and Spanish for the expression of modal meanings. For this task we have used two main sources of inspiration: a) the syntagmatic options proposed by M.A.K

\footnotetext{
${ }^{4}$ Work on modality done on the Spanish language is scarce and fragmented - in comparsion with English-, and focused mainly on the study of verbal periphrases (Silva-Corvalán 1990, Müller 2001, Cornillie 2007), and the expression of modality by means of mood and tense (Losada Durán 2000, Ridruejo 1999, Ahern 2006, Aaron 2007). Interesting contrastive work between English and Spanish is basically descriptive and not focused on practical annotation issues (see Hidalgo-Downing 2004, Alonso-Almeida 2014, Marín-Arrese 2015, to mention a few).
} 
Halliday in his systemic-functional account of modality and modulation in English (Halliday, 1970); and b) the contrastive account of modality in English and Spanish proposed in Lavid et al. (2010, chapter 4).

As will be shown in section 5 below, the resulting specification offers a fully-fledged lexicogrammatical cartography of the syntagmatic realisations of the different modal meanings proposed for English and Spanish, which will hopefully result in a much more complete characterisation of these two languages in terms of modal features.

\section{Annotation proposal: basic decisions}

As pointed out in the introduction above, the annotation of modality is not an easy task. From a purely theoretical point of view, there are a number of problems which have to be considered when dealing with this category. First, modality itself is not a unified notion, and there are different interpretations as to what counts as 'modal' among linguists, probably because originally it was approached from form to meaning, i.e., focusing on modal verbs and their meanings. Second, linguists do not agree in the number and types of modal meanings to be defined or in the meanings that are covered under certain modality types. A further complication is that that there is often no clear-cut distinction between modal and other meanings, thus creating a continuum of expressions that range from clearly modal to marginally modal. For example, the notion of willingness - one central meaning of volitional modality - is connected with the notions of liking, availability, readiness, and ability, which is also one of the central meanings of dynamic modality. Third, semantics and pragmatics are closely intertwined in the expression of modal meanings, and it is often possible to find a literal modal interpretation and a pragmatic modal interpretation. For example, the meaning of absence of obligation (You don't need to) can be used pragmatically to prohibit (You don't need to tell him), when said instead of You mustn't tell him). Finally, the relationship between negation and modal meanings is a complex one. With some modal expressions, negation does not fundamentally alter the quality of the modality being expressed. Thus, the negation of tendency is still tendency (He tends to... / He doesn't tend to...); likewise, the negation of epistemic possibility is still epistemic possibility (Perhaps she is... / Perhaps she is not...). However, when we negate obligation we can obtain two different results: either prohibition (You must do it / You mustn't do it) or the mere absence of obligation, which is a completely different type of meaning (You must do it / You don't need to do it). Similarly, when we negate an expression that intrinsically indicates negative willingness ( $I$ 
don't object to ...), the result is a different modal meaning: acceptance.

In view of the problems described above, our annotation model is based on the following assumptions:

1. We address the annotation of modality by distinguishing two interrelated dimensions: one oriented towards the semantics of modality in general, focusing on a number of prototypical modal meanings and their subtypes; the other one oriented towards the lexicogrammatical realisations of modality, focusing on the different encodings of the modal meanings in English and Spanish. This distinction allows us to capture in a principled way both the common semantic features of modality at the level of function, and the language-specific encodings of these features, at the level of form.

2. We give priority to semantics over pragmatics: we annotate the modal meaning of an expression and its syntactic encoding in both languages, and leave aside the pragmatic dimension for future annotation work.

3. In order to avoid an unnecessary proliferation of the subtypes of modality in our tagset, we do not include tags that are the result of negating another already labeled modal meaning except for 'prohibition' and 'absence of obligation', which are the result of negating 'obligation'. Consequently, we do not include tags referring to meanings such as 'impossibility' or 'inability', which are the expected result of negating 'possibility' and 'ability'. In our present proposal, only two tags contain an intrinsic meaning of negation: 'prohibition' and 'absence of obligation', which are two different meanings that result from negating 'obligation'.

In the following sections we define and describe in detail the tagsets that we propose for the annotation of modality in English and Spanish. We first present the functional semantic tagset consisting of four basic modal meanings and their subtypes (section 4). This is followed by a description of the last in a sequence of annotation experiments carried out on a bilingual sample of sentences extracted from the MULTINOT corpus (section 5), including the description of the annotated datasets (5.1), the annotation results (5.2), and the difficult cases (5.3). Finally, we present the syntactic tagset which has been elaborated and refined on the basis of the different annotation experiments (section 6). 


\section{Annotation tagset for modal meanings in English and Spanish}

For the annotation of modal meanings in English and Spanish we first designed a core tagset consisting of four basic types of modal meanings, and an extended tagset capturing the different subtypes. The groupings and the subtypes presented below in Fig. 1 below are the result of a number of preliminary annotation experiments during which we elaborated and refined the tags until we reached a consensus with respect to the basic and the secondary meanings.

As shown in Fig. 1, the tagsets are hierarchical, allowing the annotator to choose the coarser tags from the core tagset (EP, DE, DY, VO), when in doubt about the more fine-grained subtypes from the extended tagset. For example, if $\mathrm{s} /$ he is uncertain about whether a markable is 'possibility' or 'probability', s/he can simply tag it as 'epistemic' [EP] and 'non-evidential' [NEV]. The abbreviated form of each tag is given in capital letters in brackets next to the full form.

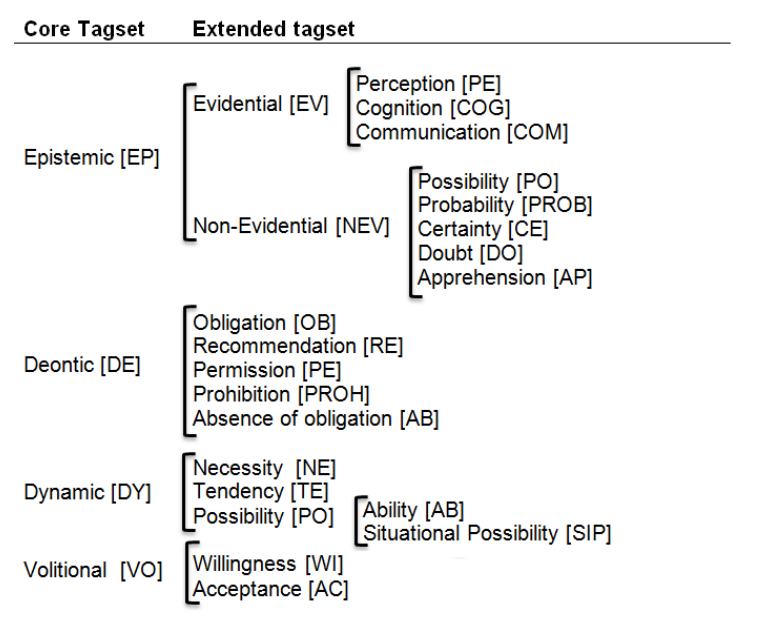

FIGURE 1 Core and extended tagsets for modal meanings in English and Spanish

Each of these modal meanings and their associated tags are described in detail in the following subsections and illustrated with examples extracted from the MULTINOT corpus.

\subsection{Epistemic Tags}

The basic tag referring to epistemic meanings is [EP]. These meanings express a qualification of the truth of a proposition (Boye, 2012), and 
are divided into two main subtypes: a) evidential meanings, defined in terms of the notion of source of information, evidence, or epistemic justification; and b) non-evidential meanings, referring to degree of certainty or epistemic support. ${ }^{5}$

For evidential meanings we use the tag $[\mathrm{EV}]$, and include all those meanings which qualify the truth of a proposition by expressing the source of the evidence that the speaker has or claims to have at his / her disposal, for or against this truth. The sources can be of three types:

1. perceptual $[\mathrm{PE}]$, referring to nonlinguistic evidence obtained through the senses), as in (11), and (12):

(11) I saw that at this end of the hall there was another chamber, just five or six feet away from where I was standing. (EOFICTION-010)I saw that at this end

(12) Todos hemos visto pobreza, hambre y dolor en nuestras sociedades. (SO-SPEECH-002)

'We all have seen poverty, hunger and pain in our societies.'

2. cognitive [COG], referring to evidence coming from knowledge by someone different from the speaker/ writer, including thoughts, beliefs and apprehension, as in (13) and (14):

(13) Martin Rees, Britain's astronomer royal, believes that there are many universes, possibly an infinite number (EO-EXPE001)

(14) Pablo sospecha que si contara uno por uno los ladrillos que dibuja a mano alzada sobre la fachada se encontraría en cada boceto con idéntica cantidad. (SO-FICTION-017)

'Pablo suspects that if he were to count the bricks drawn freehand on the façade, he would find exactly the same number on each drawing'

3. communicative $[\mathrm{COM}]$, referring to evidence coming from linguistic messages, as in (15) and (16):

(15) We often hear that overseas aid should be a government responsibility, not left to privately run charities. (EO-ESSAY010)

(16) Se dice que el poeta lírico o escribe elegías o compone himnos. (SO-ESSAY-010)

'It is said that the lyric poet either writes elegies or composes hymns.'

\footnotetext{
${ }^{5}$ For a detailed treatment of epistemicity (including both epistemic modality and evidentiality) see Lavid et al. (2016).
} 
For non-evidential meanings we use the tag $[\mathrm{NEV}]$, and we refer to those meanings concerned with the estimation of the chances of a proposition to be or become true, but not by means of qualifying evidence for or against it. The speaker/writer may express knowledge that the proposition is true or false, or else $\mathrm{s} /$ he may not be sure about its truth or falsity and therefore proceed in different ways depending on the degree of certainty conferred to the proposition:

1. express the possibility that the proposition is true (50 percent probability). Clauses with expressions of this category could be coordinated with clauses where the same expressions qualifies the same proposition with the opposite polarity or another incompatible proposition:

(17) The altar boy did not move. He was eyeing Langdon closely now. "You look familiar." Teabing huffed. "Perhaps that is because Mr. Wren comes here every year!" Or perhaps, Sophie now feared, because he saw Langdon on television at the Vatican last year. (EO-FICTION-001)

2. assign a higher degree of probability, as in (18), also including the expression of opinion through mental state predicates such as $I$ think, I suppose, and their Spanish counterparts. These expressions differ from those of possibility in that they cannot be used in coordinated constructions with the opposite polarity: one can say Maybe you're right, maybe you're not, but this is not possible with an adverb of higher probability such as probably. Higher probability, however, is compatible with expressions that deny total certainty, such as but there is no absolute certainty / but I'm not (absolutely) sure:

(18) None of such marks may be used in connection with any other product or service in a manner that is likely to cause confusion among consumers, or to disparage or discredit the owner of such mark or its affiliates. (EO-WEBP-010)

3. indicate a high degree of commitment to the truth of the proposition (almost or total certainty), as in (19):

(19) Brick hears machine guns, exploding grenades, and under it all, no doubt miles away, a dull chorus of howling human voices... (EO-FICTION-014)

The tags attached to these meanings are [POS], [PROB], and [CERT], respectively. 
Other meanings associated with this modality are the category of 'doubt' [DO], and the category of 'apprehension' [AP]. The former expresses uncertainty or lack of knowledge of the truth of the proposition, without assigning any degree of probability to it, as in (20) and (21):

(20) As you can see, we have introduced many policy measures which focus on quality rather than quantity. However, we have to ask ourselves whether we have done enough. I doubt it. (EO-SPEECH-002)

(21) Hay inmensas riquezas en la Tierra. Debemos aprovecharlas porque no sabemos cuando ha de llegar a su fin nuestra generación. (SOSPEECH-006)

'There are immense riches in the Earth. We must profit from them because we do not know when our generation will arrive at its end.'

The latter is also known as 'epistemic anxiety' (Givón, 1986) and is uncertainty combined with a positive or negative wish for or against the truth of the proposition (Lichtenberk, 1990, 293-294), as in (22) and (23):

(22) If, at the end of it all, the reader remains unpersuaded by the less conventional of the arguments that I am trying to express, it is at least my hope that she or he will come away with something of genuine value from this tortuous but, I hope, fascinating journey. (EO-EXPE-004)

(23) Espero que el compañero y querido amigo Lula no proteste (SOSPEECH-019)

'I expect that my colleague and dear Friend Lula does not complain.'

\subsection{Deontic tags}

The tags proposed for deontic meanings are [OB] for obligation, [PRO] for prohibition, [RE] for recommendation, [PE] for permission, and [ABS] for absence of obligation. Examples for each of these are provided below. Under [OB] we include those meanings stemming from social laws and conventions or human interaction. The speaker / writer may impose the deontic obligation, or else s/he may just make a statement about it. Some examples of obligation are the following:

(24) We must work for a result that means something for traders on the ground. (EO-SPEECH-003)

(25) Tendré que darte la flauta de tu abuelo. (SO-FICTION-014)

'I will have to give you your grandfather's flue.'

With the tag $[\mathrm{PRO}]$ we refer to cases of negative obligation in the sense of prohibition, as in (26) and (27): 
(26) You must not collect or harvest any personal data of any user of Google Play or of any user of other Google Services via Google Play, including account names. (EO-WEBP-005)

(27) En este sentido, no podemos ignorar la situación de los niños palestinos que sufren bajo las fuerzas israelíes de ocupación. (SOSPEECH-006)

'In that regard, we cannot ignore the plight of Palestinian children suffering under the practices of Israeli occupying forces'

For cases of recommendation we use the tag [RE], i.e., those states or events which are socially desirable, but not obligatory, because the deontic source is not entitled or does not feel it necessary to impose it. Examples for English and Spanish are provided in (28) and (29), respectively:

(28) Perhaps many people who give $\$ 1,000$ really ought to give at least $\$ 5,000$, but to blame them for not giving more could be counterproductive. (EO-ESSAY-010)

(29) entre los factores que deberían eliminarse se incluye precisamente el terrorismo mundial, (SO-SPEECH-001)

'Among the factors that should be eliminated, we find precisely world terrorism'.

For cases of permission, which express that there is neither obligation nor prohibition, we propose to use the tag $[\mathrm{PE}]$, as illustrated by (30) and (31):

(30) In these cases, to process your transaction and maintain your account, we may share your personal information with the product Provider, as permitted under the Wallet Privacy Notice. (EOWEBP-005)

(31) puedes cancelar la en cualquier momento antes de que finalice el ciclo de facturación correspondiente (STrans-WEBP-005)

'you may cancel that subscription at any time before the end of the applicable billing cycle'

Finally, we have also included the tag [ABS], for those deontic meanings referring to absence of obligation, i.e., indicating that there is neither obligation nor prohibition to perform a certain event. The difference with permission is that it is expressed by negating an obligation, thus indicating that the speaker / writer considers that the addressee believes or may believe mistakenly that the obligation exists, as shown in (32) and (33) below: 
(32) One needn't subscribe to any sort of irrationalist dogma to consent to the proposition "In the beginning was the Word." (ETransESSAY-002) 'you may cancel that subscription at any time before the end of the applicable billing cycle'

(33) no tenemos por qué buscar un defecto en la construcción de la máquina. (STrans-EXPE-008)

'We don't have to look for a flaw in the building of the machine.'

\subsection{Dynamic tags}

Dynamic modality concerns possibility and necessity derived from natural laws (i.e. those of physics, chemistry, biology, etc.), as opposed to deontic modality, which is derived from social laws. A difference may be seen in that strong deontic modality (obligation) can be disobeyed, while strong dynamic modality (necessity) cannot: for example, someone can physically smoke in a classroom even if it is forbidden (deontic modality); however, if someone cannot run very fast (dynamic modality), s/he cannot possibly disobey this limitation of nature. For dynamic modality we use the tag [DY] and include the meanings of 'necessity' [NE], 'tendency' [TE], and 'possibility' [POS] as the three main subtypes. Within 'possibility' we distinguish between 'ability' [AB] and 'situational possibility' [SIT]. These meanings are defined and exemplified below.

We use the tag [NE] to refer to meanings expressing an obligation imposed by nature; in other words, a state or event that cannot be avoided. Dynamic necessity may be due to inherent properties of an entity (34-35) or to external circumstances (36):

(34) The calling to account of world leaders which this special Assembly represents is therefore not only most timely, but absolutely necessary for the sustainability and viability of our world. (ETransSPEECH-003)

(35) Con Kate Coid era necesario ejercer mucha cautela. Era peligroso tener un antepasado como ella. (SO-FICTION-014) she (nom.)

'With Kate Coid it was necessary to be very cautious. It was dangerous to have an ancestor like her.'

(36) These are challenging times, a real stress test for the EU. The path of permanent and profound reform is as demanding as it is unavoidable. (EO-SPEECH-001)

Dynamic tendency is defined as "a natural disposition to move or act in some direction or toward some result"6 and we propose the tag [TE] to

\footnotetext{
${ }^{6} \mathrm{http}: / /$ www.wordreference.com/definition/tendency, accessed October 13, 2015 .
} 
capture these meanings in our annotation proposal. Synonyms of tendency are 'predisposition', 'proneness' or 'propensity'. The difference between tendency and habit ('usuality' in Halliday and Matthiessen (2014)) is that tendency is motivated by natural disposition, but usuality need not be so. For example, (37) expresses tendency, and hence dynamic modality, while (38) does not.

(37) Because the world has a certain stability and doesn't change capriciously, the genes that have survived in the past tend to be the ones that are going to be good at surviving in the future. (EO-EXPE-006)

(38) As my friend Tom often remarks, it's amazing how much time and money can be saved in the world of dating by close attention to detail. (EO-FICTION-012)

The following is a Spanish example of tendency:

(39) una comunidad filosófica como la nuestra,tan poco proclive al debate de ideas (SO-ESSAY-009)

'a philosophical community such as ours, so little prone to debate of ideas'

Under the tag [POS] we capture two main types of meanings:

1. those referring to 'ability' [AB], i.e., a skill that someone has acquired, normally in a voluntary way, and can activate it at will, as illustrated by (40) and (41) below:

(40) Yet the chimp feels and thinks and-according to recent experimental evidence - may even be capable of learning a form of human language. (EO-EXPE-003)

(41) SEAT encaja en esta definición y es capaz de responder a los compromisos que adquiere (SO-CORP-001)

'This definition also applies to SEAT, a company that has shown it has the capability to deliver on commitments made'

2. those referring to 'situational possibility' [SIT], i.e., the involuntary potential of someone or of something, which may eventually get activated or not. Potentiality includes inherent traits of a person or animal (for example, someone who can be moody or depressive), an inanimate entity (as a paint that can be applied with a spray) or a circumstance (possibility to go to work by underground, which depends on the location of both the place of work and the worker's home). Some examples of 'situational possibility' are the following:

(42) In some districts half the children born can be expected to die before their fifth birthday. (EO-ESSAY-010) 
(43) Así que construimos un mapa en el cual se puede hacer clic. (STrans-ESSAY-008)

'so that we construct a map in which you can click'

\subsection{Volitional tags}

The general tag that we use for volitional modality is [VO]. This refers to the expression of wish and resembles deontic modality in that it also contains an element of will. ${ }^{7}$ However, volitional modality differs from deontic modality in the following respects:

- There is no deontic source that obliges, recommends, permits or forbids;

- It is not always applied to states of affairs, as in (44) but also to propositions, especially in Spanish (45-47).

- There is a controlling agent in most cases, but not in all, as illustrated by (47) below:

(44) But we want to go further and include really all food products in our traceability and labelling rules (EO-SPEECH-002)

(45) I appreciate that Cuba's leadership wish to analyse the EU's proposal carefully (EO-SPEECH-006)

(46) Nos alegra que aumenten de manera gradual los salarios de aquellos trabajadores que laboran en las actividades con resultados más eficientes (SO-SPEECH-001)

'We would be happy to see that the salaries earned by those workers who work in those sectors recording the most efficient results and reporting benefits of particular economic and social impact are gradually increased'

(47) We have to keep this transatlantic conversation going. And that's why I wish you all a very stimulating few days here. (EO-SPEECH007)

Under volitional modality we include two main subtypes:

- Those meanings expressing 'willingness' and 'intention', which we capture with the tag [WI], as illustrated by (48) and (49), respectively. $^{8}$

(48) As I said a few days ago, we are willing to cooperate with the United States at the multilateral and bilateral levels (ETransSPEECH-001)

(49) I am going to do something unusual today. (EO-SPEECH-012)

\footnotetext{
${ }^{7}$ Biber et al. $(1999,485)$ consider it 'intrinsic' modality, together with obligation.

${ }^{8}$ Here we follow Coates' distinction (Coates, 1983, 173-174).
} 
- Those meanings expressing the acceptance of both the occurrence and the non-occurrence of a state or event, which we capture with the $\operatorname{tag}[\mathrm{AC}]$. This meaning is not often found in accounts of modality, probably due to its lack of grammatical realisations in English and other European languages. Its inclusion in modality was proposed in Carretero (1992), and it is also included in Carretero et al. (2007). Acceptance can have states of affairs in its scope (50-51), or, more rarely, propositions (52):

(50) Then I don't mind if I am in the same room as them (EOFICTION-009)

(51) Pues bien, no me importa hacerlo una vez más (SO-FICTION011)

'All right, I don't mind doing it one more time.'

(52) The random mating model is even more unrealistic. Never mind. We set up models to see what happens under ideally simplified conditions. (EO-EXPE-006)

\section{Annotation experiment}

In this section we describe the latest in a series of annotation experiments carried out to test the reliability of the core and extended tags for modal meanings proposed in the functional-semantic tagset described above. ${ }^{9}$ We first present the datasets and the annotation procedure (5.1) and then provide the results of the agreement study performed on the annotated dataset (5.2).

\subsection{Datasets and procedure}

We compiled two datasets for the annotation experiment, one containing two hundred English sentences and the other two hundred Spanish sentences, all of them extracted from original texts of the MULTINOT corpus. The extracted sentences contained potential triggers for each of the main modal meanings proposed in our functional-semantic tagset and similar proportions of grammatical categories which could potentially encode such meanings (e.g.: verbs, nouns, adjectives and adverbs). The potential modal triggers were highlighted in each of the examples of the annotation sheets so that annotators could assign one of the modal tags of our functional-semantic tagset. ${ }^{10}$ The potential triggers were compiled from different sources (e.g.: examples and descrip-

\footnotetext{
${ }^{9}$ In all the experiments there were two annotators (two of the authors of this paper) working independently and then meeting with the third author to discuss the annotation choices.

${ }^{10} \mathrm{An}$ example of one of the annotation sheets is included in the Appendix at the end of the paper.
} 


\begin{tabular}{llll} 
VERB & ADJECTIVE & ADVERB & NOUN \\
\hline can & able & possibly & ability \\
could & unable & potentially & capacity \\
tend & capable & necessarily & tendency \\
must & incapable & inevitably & obligation \\
have to & apt & & necessity \\
need & potential & & \\
& prone & & \\
& inclined & & \\
& inevitable & & \\
& avoidable & &
\end{tabular}

TABLE 1 Central triggers of English dynamic modality

\begin{tabular}{|l|c|c|c|c|c|}
\cline { 2 - 6 } \multicolumn{1}{c|}{} & Epi/Evi & Deo & Dyn & Vol & Non-Modal \\
\hline Epi/Evi & 80 & 0 & 4 & 0 & 6 \\
\hline Deo & 0 & 82 & 9 & 0 & 4 \\
\hline Dyn & 2 & 4 & 95 & 5 & 0 \\
\hline Vol & 0 & 1 & 3 & 87 & 0 \\
\hline Non-Modal & 3 & 2 & 2 & 0 & 11 \\
\hline
\end{tabular}

TABLE 2 Overall inter-annotator agreement for basic modal types

tions provided in the literature on modality, English thesauri, and the Cambridge and Oxford online dictionaries) and grouped into four main grammatical types: nouns, verbs, adjectives and adverbs. As an illustration, Table 1 shows a list of central triggers for dynamic modality in English. Similar tables were compiled for each of the modal meanings of our tagset.

\subsection{Annotation results}

The annotation experiment yielded interesting results, both at a more general and contrastive level and also at the more specific one.

First, the overall interannotator agreement for the basic modal types in both the English and the Spanish annotated datasets was very high (88.75\%), i.e. annotators agreed in 355 out of 400 annotated examples, as graphically illustrated in Table 2. The Cohen's kappa coefficient is 0.854 , indicating that there is a $85.4 \%$ chance that the agreement is not due to chance.

Second, when looking at the individual interannotator agreement in the English and the Spanish datasets separately, we find that it was also high: in the English dataset the number of agreements was $88.50 \%$ 


\begin{tabular}{|l|c|c|c|c|c|}
\cline { 2 - 6 } \multicolumn{1}{c|}{} & Epi/Evi & Deo & Dyn & Vol & Non-Modal \\
\hline Epi/Evi & 42 & 0 & 0 & 0 & 4 \\
\hline Deo & 0 & 40 & 4 & 0 & 2 \\
\hline Dyn & 1 & 2 & 47 & 4 & 0 \\
\hline Vol & 0 & 1 & 1 & 43 & 0 \\
\hline Non-Modal & 1 & 1 & 2 & 0 & 5 \\
\hline
\end{tabular}

TABLE 3 Inter-annotator agreement for English dataset

\begin{tabular}{|l|c|c|c|c|c|}
\cline { 2 - 6 } \multicolumn{1}{c|}{} & Epi/Evi & Deo & Dyn & Vol & Non-Modal \\
\hline Epi/Evi & 38 & 0 & 4 & 0 & 2 \\
\hline Deo & 0 & 42 & 5 & 0 & 2 \\
\hline Dyn & 1 & 2 & 48 & 1 & 0 \\
\hline Vol & 0 & 0 & 2 & 44 & 0 \\
\hline Non-Modal & 2 & 1 & 0 & 0 & 6 \\
\hline
\end{tabular}

TABLE 4 Inter-annotator agreement for Spanish dataset

and the Cohen's kappa coefficient was 0.851, as shown in Table 3.

In the Spanish dataset the number of agreements was $89.00 \%$ and the Cohen's kappa coefficient was 0.857, as shown in Table 4.

Such similarity in the agreement rates for both datasets suggests that the core modal values defined in our tagset are adequate for both languages and that English and Spanish are comparable in the modal meanings they express. When analyzing how well the annotators distinguished the different subtypes within each of the main modal types (e.g.: prohibition, permission, obligation, etc..), we found high rates of agreement between annotators in both the English and the Spanish datasets, as illustrated in Tables 5 and 6 .

These high agreement values indicate that the tagsets for modal meanings in English and Spanish are reliable and can be expected to produce similar results when used by different annotators. However, the annotation experiment also revealed difficult cases and problems in

\begin{tabular}{|l|c|c|}
\cline { 2 - 3 } \multicolumn{1}{c|}{} & $\begin{array}{c}\text { Number of } \\
\text { agreements }(\%)\end{array}$ & $\begin{array}{c}\text { Cohen's kappa } \\
\text { coefficient }\end{array}$ \\
\hline Epistemic/Evidential modality & $84.00 \%$ & 0.792 \\
\hline Deontic modality & $80.00 \%$ & 0.837 \\
\hline Dynamic modality & $94.00 \%$ & 0.868 \\
\hline Volitional modality & $86.00 \%$ & 0.787 \\
\hline
\end{tabular}

TABLE 5 Inter-annotator agreement within modal subtypes in English 


\begin{tabular}{|l|c|c|}
\cline { 2 - 3 } \multicolumn{1}{c|}{} & $\begin{array}{c}\text { Number of } \\
\text { agreements }(\%)\end{array}$ & $\begin{array}{c}\text { Cohen's kappa } \\
\text { coefficient }\end{array}$ \\
\hline Epistemic/Evidential modality & $76.00 \%$ & 0.703 \\
\hline Deontic modality & $84.00 \%$ & 0.880 \\
\hline Dynamic modality & $96.00 \%$ & 0.875 \\
\hline Volitional modality & $88.00 \%$ & 0.816 \\
\hline
\end{tabular}

TABLE 6 Inter-annotator agreement within modal subtypes in Spanish

the annotation process, as outlined in section 5.3 below.

\subsection{Difficult cases}

The difficult cases encountered in the annotation experiment can be divided into two main types:

1. Cases where there was a degree of overlap in the modal meanings expressed by the triggers, such as modal auxiliaries (can, may, might, must, etc.) in English and their counterparts in Spanish (poder, deber, tener que), as well as with some related adjectives (possible). These items are polysemous, i.e., they tend to express more than one modal meaning (must: obligation, necessity, prohibition; can: permission, ability, situational possibility, prohibition), and this can give rise to potential disagreement between annotators. Fuzzy areas in the boundaries between modal meanings occur, for example, in the case of dynamic possibility and epistemic possibility. In certain contexts, such as the one illustrated in (53), it is hard to decide if the writer is describing what is compatible with the world (dynamic possibility) or if $\mathrm{s} /$ he is stating that something could happen in the future (epistemic possibility).

(53) Gracias a las cookies, resulta posible que el Ministerio de la Presidencia reconozca los navegadores de los usuarios después de que éstos hayan accedido y ofrezca información específica derivada de visitas anteriores. (MULTINOT SO-WEB-001)

'Through the use of cookies, it is possible for the Ministry of the Presidency to recognise specific browsers when they access the web portal and offer specific information based on previous visits.'

Another interesting area of overlap is found between dynamic possibility and deontic permission. Both English and Spanish use the meaning of possibility to indicate that someone is allowed to do something. This use is so conventionalized in both languages that it is doubtful whether it should classified as a pragmatic 
inference anymore. Example (54) provides an example of this kind of example that provoked disagreement.

(54) Usted tendrá la posibilidad de ejercer los derechos de acceso, rectificación, cancelación y oposición de sus datos personales que obran en los ficheros de la Seguridad Social, solicitándolo por cualquier medio que deje constancia de su envío y de su recepción. (SO-WEB-016)

'You will be able to exercise your rights to access, amend, cancel and oppose your personal data recorded in the Social Security files, requesting to do so by any means that records the sending and receipt of your request. To exercise your rights, you can contact the Social Security in writing using the Suggestions and Complaints form.'

Another area of disagreement involving dynamic modality is illustrated by example (55). The cause of this type of disagreement is that in both languages we can find adjectives that literally refer to ability and potential attributed to a participant (ready, prepared), but they are often used to show willingness rather than mere ability.

(55) Port Aransas is the only established town on Mustang Island, and it's the fishing capital of Texas. Plenty of guides and charters are ready to take you out and demonstrate why; four lighted piers allow fishing by day and night. (EO-TOU-101)

The next important problematic area concerns epistemic certainty and evidential cognition. In our experiments we could identify the cognitive type of evidentiality as a particularly problematic category, given the nature of the evidence it provides. Thus, while perception and communication seem to be distinct from any other epistemic meaning, the internal nature of the evidence present in cognition makes it very hard to distinguish from epistemic meanings such as certainty, giving rise to disagreements in the annotation. In example (56), for instance, some annotators might interpret the sentence as meaning that Google has certain knowledge about a matter (epistemic modality), while others may understand that Google has evidence that something is the case.

(56) Google may warn you if it considers the app to be unsafe, or block its installation on your device if it is known to Google to be harmful to devices, data or users. (EO-WEB-005)

The last problematic area we will mention here involves the distinction between dynamic ability and dynamic possibility. This 
difficulty stems from the fact that very often it was impossible for the annotators to decide whether the potential predicated in the sentence derived from one participant's skills or from general enabling circumstances, as illustrated in (57).

(57) Dating Concestor o, the most recent common ancestor of all living humans, is not a task that can be undertaken by a practising genealogist. It is a task in estimation: a task for a mathematician. (EO-EXPE-006)

Examples like (57) seem to be vague rather than ambiguous, in the sense that the two meanings are present and there is no question of choosing one of them. This vagueness led us to include a more general tag (dynamic possibility) covering both ability and situational possibility.

2. Cases where annotators disagree on the modal nature of the triggers. This group includes mostly lexical verbs, adjectives and nouns such as prohibit, necessary or obligation which have a meaning that is closely related to one of the modality types.

Our experiments showed that the real challenge with these triggers is deciding whether they express a modal meaning or not. This is because these words are little or not grammaticalized at all, and while some of their uses are equivalent to modal constructions, as in (58), other uses are clearly non-modal, as in (59):

(58) we feel ourselves to be under a greater obligation to help those whose misfortunes we have caused. (EO-ESSAY-010)

(59) the United States is not living up to its obligations (EOESSAY-003)

The analysis of the cases that were not unanimously identified as modal or non-modal led us to identify three characteristics of modality that are relevant to explain discrepancies between annotators. These characteristics could be said to define a prototypical instance of modality:

- Modality typically has a clausal scope.

- All modalities, except for epistemic cases, refer to potentialities of the participant, i.e. what a participant must/can/wants/tends to do, but not to what that participant is actually doing.

- Modality is a grammatical category, typically realized through highly grammaticalized expressions such as the English modal auxiliaries and Spanish periphrases. 
Whenever any of these characteristics is compromised, the example looks less typically modal, potentially leading to disagreement between annotators. Let us consider some examples of this.

Examples (60) and (61) are unproblematic because one can easily identify a clause to which the modal meanings of willingness and possibility are respectively applied.

(60) people would be willing to pay for a given service (EOESSAY-006)

(61) Es posible que Renfe-Operadora le facilite el acceso a otras páginas web que consideramos pueden ser de su interés. (SOWEBP-009)

'[it] Is possible that Renfe-Operadora will give you access to other webpages we think might be of your interest'

For the same reason, (62) is clearly identified as non-modal, since there is no trace of a clause to which modality could apply.

(62) Elementary distinctions - some versus all, probable versus always, is versus ought - are eagerly flouted to paint human nature as an extremist doctrine and thereby steer readers away from it. (EO-EXPE-008)

Similarly, modal expressions whose scope is a Nominal Group that nominalizes an action (e.g. arrival, acquisition) also seem to be perceived as close to the prototypical instance of modalization. However, nouns that are clearly not nominalizations can appear in a context that suggests an implicit clause. In (63), for instance, the noun product allows us to understand a clause like to have/buy/etc. from the context, leading to potential differences in judgement: Is this clause understood from the context enough to claim that want has a modal function in (63) or should the annotator dimiss this example as non-modal on the grounds that there is no explicit clause to which the modal meaning applies?

(63) Find the products you want (EO-WEB-007)

In our view, there are two possible solutions to this problem, and both involve replacing the simple tag pair Modal/Non-Modal by the following descriptive set of options:

(a) The example contains an explicit clause (finite or non-finite) to which modality applies.

(b) The example contains a noun denoting an action or state to which modality applies. 
(c) The example contains an implicit clause that can be recovered from the previous text.

(d) The example contains a noun that does not denote an action or state, but a clause can be inferred or understood from the context and is suggested by the noun.

(e) The example does not contain anything resembling a clause, either explicit or implicit.

In the first solution, we can opt for an arbitrary boundary that establishes what counts as modal. For example, cases a), b) and c) could be covered by our tag Modal, while d) and e) would be left out. This is the solution we often find in linguistic studies.

Conversely, we could include the selection from the listed set of options as part of the taggings. That is, instead of simply adding the tags Modal/Non-Modal to an example, this could be replaced by Modal(a), Modal(b), etc. This has the advantage that the annotation of the corpus does not contain a preconception of what should be considered modal or not, allowing the user to decide what examples to retrieve based on his/her own criteria.

Together with the problems involved in the identification of a clausal scope, the fact that some items are not fully grammaticalized is a common cause of disagreement between annotators. Typical realizations of modality, such as modal verbs, are so grammaticalized that they express vague modal meanings incompatible with qualifications. For example, the type of obligation denoted by must is much more general than that of the noun obligation, as evidenced by the fact that must can also be used to give advice or to make an invitation. In addition, the sense of obligation denoted by the noun obligation can be qualified in great detail, through the modification of adjectives such as legal, moral, etc, or even used in the plural form to denote a set of obligations. In our experiments we observed that the presence of qualification was a common cause of disagreement between annotators when deciding if the example should be tagged as modal or non-modal. The reason for this could be that on the one hand these examples contain meanings clearly related to modal meanings, while on the other hand they show a characteristic that is not found in typical instances of modality.

Similarly, we observed in our experiments that those examples containing constructions normally used to describe potentialities of a participant are less problematically identified as modal. Such constructions include: 
- Processes of possession, where the modal trigger is the possessed participant, as in (64):

(64) Y en Brasil tenían la obligación de asistir a misa. (SOEXPE-013)

'And in Brazil [they] had the obligation of attending the mass'

- Processes of attribution, where the modal trigger is a quality ascribed to a participant or to a clause, as in (65) and (66):

(65) Europe is ready to give more than others. But it is not willing to get nothing in return. (EO-SPEECH-003)

(66) Si nosotros no pudiéramos eliminar las toxinas del cuerpo, es probable que no sobreviviéramos más de una semana. (SO-POPSCI-005)

'If we could not eliminate the toxins from-the body, [it] is probable that [we] would not survive longer than a week.'

- Processes of metaphorical location, where the modal trigger is a metaphorical place referring to a situation in which a participant finds itself., as in (67):

(67) se vean en la necesidad de respetarla y amarla. (SOESSAY-006)

'[they] see themselves in the need of respecting and loving it.'

- Processes of existence, where the modal trigger is the existent, as in (68).

(68) only by integrating more can we really reach our objectives. There is no doubt about it. (EO-SPEECH-001)

\section{Implementation}

In this section we focus on current work on the implementation of the proposed annotation model and on the procedures which will be followed for the large-scale annotation of the English and the Spanish texts of the MULTINOT corpus.

The annotation tool selected is the UAM CorpusTool 3, given its user-friendliness and the additional functionalities it provides for quantitative analysis. ${ }^{11}$

Fig. 2 shows the current state of the implementation of our annotation scheme, designed in the form of two simultaneous system

\footnotetext{
${ }^{11}$ The UAM Corpus Tool is freely available at (http://www.corpustool.com/), and allows to perform both automatic and manual annotation.
} 
networks: MODAL-SEMANTICS, capturing the functional-semantic tagset, and MODAL-SYNTACTIC-REALIZATION, capturing the syntactic tagsets.

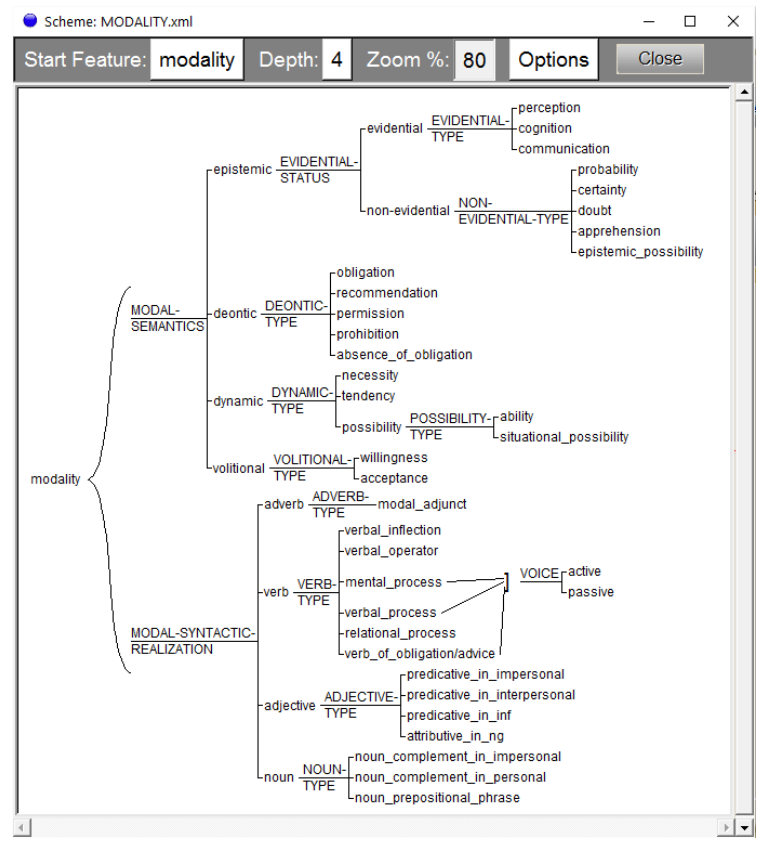

FIGURE 2 Implementation of modal tagsets in UAM Corpus Tool

These two system networks are not mutually exclusive, as indicated by a curly bracket. Consequently, when annotating a trigger the user first exhausts the choices which depend on the MODAL-SEMANTICS network and then continues with the choices which depend on the MODAL-SYNTACTIC-REALIZATION network. Each of the choices in the networks refers to a tag in our annotation model, and all the tags are organized in dependency systems that contain mutually exclusive choices. Each selected tag takes the user to systems with more specific tags, until the path in the network comes to an end. At the end of the process, the annotation produced contains the collection of tags from the network that characterize the semantic and the syntactic features of the trigger.

Concerning the annotation process itself, the experiments revealed that it is possible to use both automatic and manual annotation methods depending on the nature of the triggers, as follows: 
1. One first group of triggers can be automatically annotated without human intervention. It is the case of items like perhaps, probably, maybe and their Spanish counterparts. These can be automatically annotated with specific modal tags because they express only one type of modality and they always appear in the same constructions. For instance, all the instances of the adverb perhaps can be annotated with the following tags: epistemic/nonevidential/possibility and adverb/modal-adjunct. Such automatic annotation is performed by a function available in UAM CorpusTool 3 that allows the user to associate a string with a collection of tags from the coding scheme, as shown in Fig. 3.

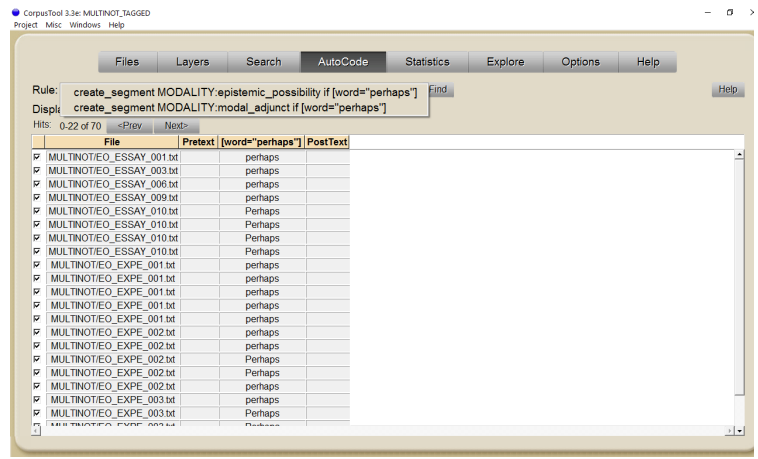

FIGURE 3 Autocoding in UAM Corpus Tool

2. A second group of triggers can be automatically annotated with the most general tags. This is the case of modal verbs that are specialized in the expression of modality but are polysemous. Here, the annotation is first done automatically and later the human annotator can complete the annotation by manually choosing the more specific tags. Fig. 4 shows an example with the modal verb must. This verb automatically received the tags Modality, Verb and Verbal-operator (highlighted in red), and a menu guides the annotator through the systems for which a decision is still to be made (highlighted in blue).

3. A third group of triggers consists of lexical items in which human intervention is crucial to decide if they express modality or not. Once this decision is made, the annotation of the more specific tags can be done automatically. Here we find mostly lexical verbs such as oblige or force and nouns such as tendency or prohibition, which are semantically related to modal meanings, but are 


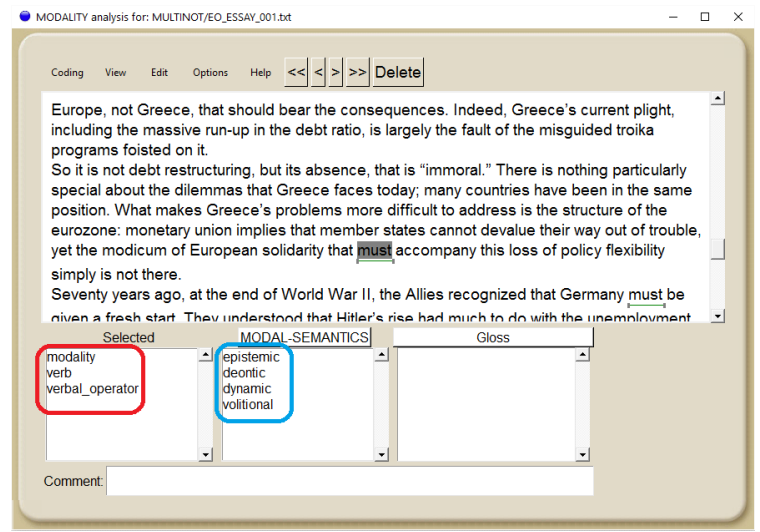

FIGURE 4 Partial automatic annotation

not grammaticalized. In cases like this, automatic annotation can be provided except for the more general decision concerning the modal use of the trigger in a particular example, as shown in Fig. 5 .

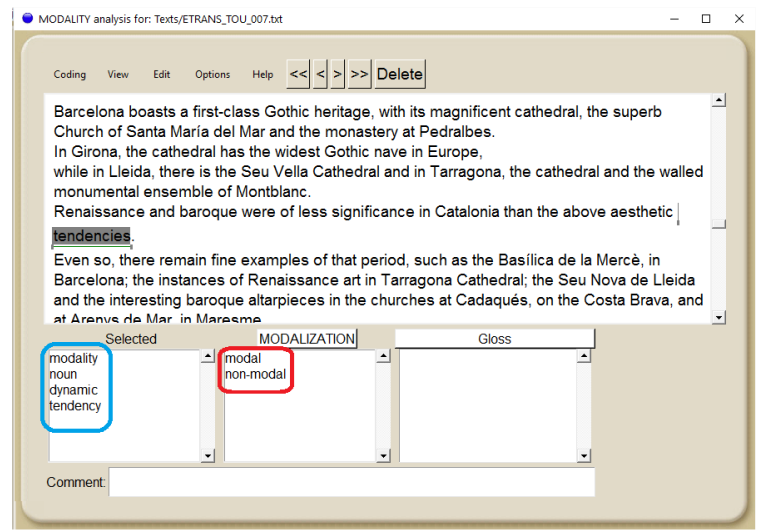

FIGURE 5 Partial automatic annotation for tendencies

In this example, the tags highlighted in blue have been automatically assigned to the potential trigger tendencies, whereas the decision between modal and non-modal is left to manual annotation (highlighted in red). Since the selection of the tag non-modal makes the rest of tags irrelevant to that particular example, they 
are subsequently deleted when the non-modal tag is chosen.

The annotations implemented with this tool can be exported and reused by other programs in a standard xml version:

(69) yet the modicum of European solidarity that <segment id='1' features='modality;deontic;obligation;verb;verbal-operator' $>$ must $</$ segment $>$ accompany this loss of policy flexibility simply is not there.

\section{Conclusion and future work}

In this paper we have reported on current work on the design, validation, and implementation of a linguistically-motivated annotation model of modality in English and Spanish in the framework of the MULTINOT project. In this project, aimed at the creation of a richlyannotated bilingual English-Spanish corpus consisting of original and translated texts, the annotation of modal values and their realisations is an important task, not only from a contrastive and translational point of view, but also for its computational relevance in the NLP community, where modally-annotated corpora are an indispensable resource for training systems to automatically interpret modality.

In order to capture not only the modal meanings which are common between English and Spanish, but also their language-specific realisations in both languages, we have designed an annotation model consisting of two interrelated tagsets: a functional-semantic tagset, capturing four basic modal meanings and their subtypes, and a languagespecific tagset, providing a fine-grained characterisation of the syntactic realisations of those meanings in English and Spanish. The proposed functional-semantic tagset is the result of various rounds of annotation experiments to refine and validate its reliability for the large-scale annotation of English and Spanish texts. In the paper we describe the latest experiment carried on a bilingual sample dataset from the MULTINOT corpus, where we found high interannotator agreement rates for both the coarser functional-semantic tags as well as for the more specific subtypes. These results indicate that the proposed tags are reliable, though some problems and difficult cases were encountered during the annotation process. These can be grouped into two main types: a) cases where there was a degree of overlap in the modal meanings expressed by the triggers, such as modal auxiliaries (can, may, might, must, etc.) in English and their Spanish counterparts; b) cases where annotators disagree on the modal nature of the triggers. This group includes mostly lexical verbs, adjectives and nouns such as 'prohibit', 'necessary' or 'obligation' which have a meaning that that belongs to one of the modality 
types. In the paper we discuss each of these cases in detail and indicate possible ways to solve ambiguities when confronted with them in the annotation process.

Current work is focused on the implementation of the proposed scheme for the large-scale annotation of the bilingual texts of the MULTINOT corpus using both automatic and manual procedures, as described in the last section of the paper. Given the register diversity of MULTINOT corpus and the fact that it includes both original and translated texts, it is expected that the modal annotations to be carried out in the upcoming months will be a useful resource for both the linguistic and the NLP communities.

\section{Acknowledgments}

We would like to thank the reviewers and the editorial team for their insightful and helpful remarks, which have led us to improve the overall organization and clarity of the paper.

\section{References}

Aaron, Jessi Elana. 2007. El futuro epistémico y la variación: gramaticalización y expresión de la futuridad desde 1600. Moenia 13:253-274.

Ahern, Aoife. 2006. Spanish mood, metarepresentation and propositional attitudes. In K. von Heusinger and K. Turner, eds., Where Semantics Meets Pragmatics, pages 445-471. Amsterdam: Elsevier.

Alonso-Almeida, Francisco. 2014. Evidential and epistemic devices in English and Spanish medical, computing and legal scientific abstracts: A contrastive study. In M. Bondi and R. Lorés, eds., Abstracts in Academic Discourse. Variation and Change. Bern: Peter Lang.

Baker, K., M. Bloodgood, B. J. Dorr, C. Callison-Burch, N. W. Filardo, C. Piatko, L. Levin, and S. Miller. 2012. Use of modality and negation in semantically informed syntactic MT. Computational Linguistics 38:1-28.

Biber, Douglas, Stig Johansson, Geoffrey Leech, Susan Conrad, and Edward Finnegan. 1999. Longman Grammar of Spoken and Written English. London: Longman.

Boye, Kasper. 2012. Epistemic Meaning: A Crosslinguistic and FunctionalCognitive Study. Empirical Approaches to Language Typology 43. De Gruyter Mouton: Berlin and Boston.

Burchardt, A. and A. Frank. 2006. Approximating Textual Entailment with LFGandFrameNetFrames. In R. Bar-Haim, I. Dagan, B. Dolan, L. Ferro, D. Giampiccolo, B. Magnini, and I. Szpektor, eds., Proceedings of the Second PASCAL Challenges Workshop on Recognising Textual Entailment, pages $92-97$. Venice, Italy.

Carretero, Marta. 1992. Una propuesta de tipología de la modalidad: la aceptación como categoría modal. Dicenda 10:41-61. 
Carretero, M and J. R. Zamorano-Mansilla. 2013a. An analysis of disagreement-provoking factors in the analysis of epistemic modality and evidentiality: the case of English adverbials. pages 16-23. Potsdam, Germany: Association for Computational Linguistics.

Carretero, M. and J. R. Zamorano-Mansilla. 2013b. Annotating English adverbials for the categories of epistemic modality and evidentiality. In J. I. Marín-Arrese, M. Carretero, J. A. Hita, and J. van der Auwera, eds., English Modality Core, Periphery and Evidentiality, pages 317-355. Berlin and New York: De Gruyter Mouton.

Carretero, Marta, Juan Rafael Zamorano-Mansilla, Francisco Nieto, Cristina Alonso, Jorge Arús, and Asución Villamil. 2007. An Approach to Modality for Higher Education Studies of English. In M. Genís, E. Orduna, and D. García-Ramos, eds., Panorama de las lenguas en la enseñanza superior. ACLES 2005, pages 91-101. Madrid: Universidad Antonio de Lebrija.

Coates, Jennifer. 1983. The Semantics of the Modal Auxiliaries. London: Croom Helm.

Collins, Peter. 2009. Modals and quasi-modals in English. Amsterdam: Rodopi.

Cornillie, Bert. 2007. Evidentiality and Epistemic Modality in Spanish (Semi) Auxiliaries. A Cognitive Functional Approach. Berlin: Mouton de Gruyter.

Givón, Talmy. 1986. Syntax: An Introduction.. Amsterdam: John Benjamins Publishing.

Halliday, M.A.K. 1970. Functional diversity in language, as seen from a consideration of modality and mood in English. Foundations of Language 6.3:322-361. Reprinted in part as "Modality and modulation in English" in Gunther Kress (ed.) 1976. Halliday: System and function in language. Selected papers, Oxford University Press. 189-213.

Halliday, M.A.K. and C.M.I.M. Matthiessen. 2014. Introduction to Functional Grammar. London and New York: Routledge.

Hendrickx, I., A. Mendes, and S. Mencarelli. 1973. Modality in text: A proposal for corpus annotation. In N. Calzolari, K. Choukri, T. Declerck, M. U. Doğan, B. Maegaard, J. Mariani, A. Moreno, J. Odijk, and S. Piperidis, eds., Proceedings of the Eighth International Conference on Language Resources and Evaluation - LREC 2012, pages 1805-1812. Istanbul: European Language Resources Association ISBN 978-2-9517408-7-7 EAN 978295174087.

Hidalgo-Downing, Laura. 2004. Non-verbal markers of modality and evidentiality and the expression of writer stance in a comparable corpus of English and Spanish editorials and news articles. In J. I. M. Arrese, ed., Perspectives on Evidentiality and Modality, pages 205-228. Editorial Complutense.

Karttunen, Lauri and Annie Zaenen. 2005. Veridicity. In Dagstuhl Seminar Proceedings 05151: Annotating, Extracting and Reasoning about Time and Events. http://drops.dagstuhl.de/opus/volltexte/2005/314. 
Lavid, Julia, Jorge Arús, Bernard DeClerck, and Veronique Hoste. 2015. Creation of a High-quality, Register-diversified Parallel Corpus for Linguistic and Computational Investigations. Procedia - Social and Behavioral Sciences 198:249-256.

Lavid, Julia, Jorge Arús, and Juan Rafael Zamorano-Mansilla. 2010. Systemic-Functional Grammar of Spanish. A Contrastive Study with English. London and New York: Continuum.

Lavid, Julia, Marta Carretero, and Juan Rafael Zamorano-Mansilla. 2016. Contrastive Annotation of Epistemicity in the Multinot Project: Preliminary Steps. In H. Bunt, ed., Proceedings of the ISA-12, Twelfth Joint ACL - ISO Workshop on Interoperable Semantic Annotation, held in conjunction with Language Resources and Evaluation Conference 2016. Portorov, Slovenia.

Lichtenberk, Frantisek. 1990. Apprehensional Epistemics. In J. Bybee and S. Fleischman, eds., Modality in Grammar and Discourse, Typological Studies in Language (TSL)Number 32, pages 293-327. Amsterdam and Philadelphia: John Benjamins.

Losada Durán, José Ramón. 2000. Los tiempos de futuro y la modalidad en español y en inglés. Vigo: Servicio de Publicaciones de la Universidad de Vigo.

Marín-Arrese, Juana I. 2015. Epistemicity and stance: A cross-linguistic study of epistemic stance strategies in journalistic discourse in English and Spanish. Information, Infons, and Inference. Discourse Studies 17.2:210225.

McShane, Marjorie, Sergei Nirenburg, and Ron Zacharski. 2004. Mood and modality: Out of the theory and into the fray. Natural Language Engineering 19.1:57-89.

Müller, Henrik Høeg. 2001. The Spanish modal auxiliaries. Copenhagen Studies in Languages 26:39-66.

Nissim, Malvina, Paola Pietrandrea, Andrea Sansò, and Caterina Mauri. 2013. Cross-linguistic annotation of modality: A data-driven hierarchical model. In H. Bunt, ed., Proceedings of the 9th Joint ISO - ACL SIGSEM Workshop on Interoperable Semantic Annotation (isa-9), pages 7-14. Potsdam.

Nuyts, Jan. 2005. The Modal Confusion: On Terminology and the Concepts Behind it. In A. Klinge and H. H. Müller, eds., Modality: Studies in Form and Function, pages 5-38. London: Equinox.

Palmer, Frank R. 1990. Modality and the English Modals. London and New York: Longman.

Perkins, Michael R. 1983. Modal Expressions in English. London: Frances Pinter.

Portner, Paul. 2009. Modality. Oxford: Oxford University Press.

Ridruejo, Emilio. 1999. Modo y Modalidad. El Modo en las Oraciones Subordinadas Sustantivas. In I. Bosque and V. Demonte, eds., Gramática 
Descriptiva de la Lengua Española, Vol. 2, pages 3209-3252. Madrid: Espasa Calpe.

Saurí, Roser and James Pustejovsky. 2009. Factbank: A Corpus Annotated with Event Factuality. Language Resources and Evaluation 43.3:227-268.

Saurí, Roser, Marc Verhagen, and James Pustejovsky. 2006. Annotating and Recognizing Event Modality in Text. In Proceedings of the 19th International FLAIRS Conference, pages 333-339. Florida.

Silva-Corvalán, Carmen. 1990. Contextual Conditions for the Interpretation of 'Poder' and 'Deber' in Spanish. In J. Bybee and S. Fleischman, eds., Modality in Grammar and Discourse, Typological Studies in Language (TSL)Number 32, pages 67-105. Amsterdam and Philadelphia: John Benjamins.

Szarvas, György, Veronika Vincze, Richárd Farkas, and János Csirik. 2008. The BioScope Corpus: Annotation for Negation, Uncertainty and their Scope in Biomedical Texts. In BioNLP ACL-2008 Workshop.

Wiebe, Janyce, Theresa Wilson, and Claire Cardie. 2005. Annotating Expressions of Opinions and Emotions in Language. Language Resources and Evaluation 73. 2-3:165-210.

Zamorano-Mansilla, Juan Rafael and Marta Carretero. 2012. An Annotation Scheme for Dynamic Modality in English and Spanish. Linguistics and the Human Sciences 6:282-304. 



\section{Appendix}

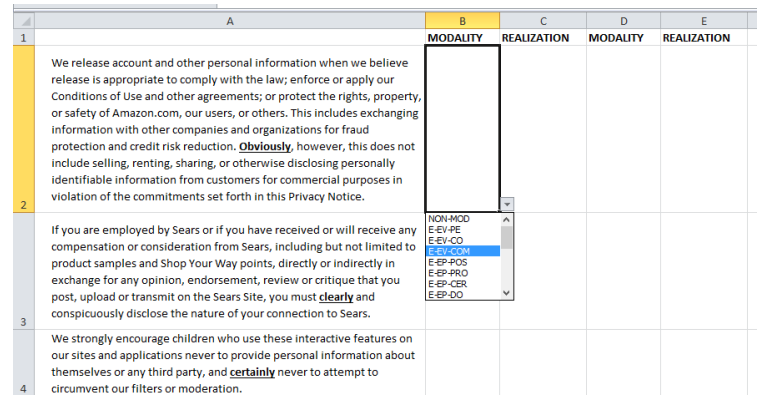

FIGURE 1 Example of document for experimental annotation of examples containing a potential modal trigger 